\section{RMD Open}

Rheumatic \&

Musculoskeletal Diseases

To cite: Ferraccioli $\mathrm{G}$, Tolusso B, Fedele AL, et al. Do we need to apply a T2T strategy even in ACPAnegative early rheumatoid arthritis? YES. RMD Open 2016;2:e000263.

doi:10.1136/rmdopen-2016000263

- Prepublication history for this paper is available online. To view these files please visit the journal online (http://dx.doi.org/10.1136/ rmdopen-2016-000263).

Received 13 February 2016 Revised 6 March 2016 Accepted 9 March 2016

\section{SLinked}

- http://dx.doi.org/10.1136/ rmdopen-2015-000143

\section{CrossMark}

Division of RheumatologyFondazione Gemelli, Institute of Rheumatology and Affine Sciences, School of Medicine, Catholic University of the Sacred Heart, Rome, Italy

Correspondence to Professor Gianfranco Ferraccioli; gf.ferraccioli@rm.unicatt.it

\title{
Do we need to apply a T2T strategy even in ACPA-negative early rheumatoid arthritis? YES
}

\section{Gianfranco Ferraccioli, Barbara Tolusso, Anna Laura Fedele, Elisa Gremese}

Over the past 10 years, the clinical and therapeutic approach to rheumatoid arthritis (RA) has tremendously improved the outcomes of patients, thanks to the recommendations on how to deal with early $\mathrm{RA},{ }^{1}$ on how to treat and monitor patients, ${ }^{2}$ and on how to assess predictors of response or of progression and non-response to initial therapy with conventional synthetic disease modifying antirheumatic drugs (csDMARDs). ${ }^{3}$ These predictors have been well defined over the years and include: (A) high-disease activity; (B) autoantibody positivity (rheumatoid factor and/or antibodies to citrullinated proteins) and (C) the early presence of joint damage. ${ }^{3}$

The logical consequence of the eighth recommendation on the management of $\mathrm{RA}^{2}$ would be to deal carefully with patients whether presenting with or without the risk factors B and C. Yet no data are available on treating patients with RA presenting with or without risk factors $\mathrm{B}$ and $\mathrm{C}$ differently. None of the trials in recent years have initially separated patients with $\mathrm{RA}$ with and without risk factors $\mathrm{B}$ and $\mathrm{C}$ to see whether these patients, respectively, behave differently in terms of major outcomes (remission, joint damage and disability).

Surrogate information can be obtained from randomised controlled clinical trials (RCTs) in which patients with and without all risk factors were enrolled. Looking at the long-term extension, these trials could reveal whether the risk factors really determine different outcomes in terms of gain of function and protection from joint damage, and therefore whether different approaches should be established at diagnosis.

One of the trials that gives important clues on how to properly treat patients with early RA has been the BeST trial. ${ }^{4}$ This trial has reached the 10th year of follow-up and can therefore amply provide key information on the medium to long-term course of early RA.
The rule adopted over the past few years has been the treat-to-target (T2T) strategy. ${ }^{2}$ Among the overarching principles of the T2T strategy, principle B states that "the primary goal of treating patients with RA is to maximise long-term health-related quality of life through control of symptoms, prevention of structural damage, normalisation of function, and participation in social and work-related activities".

To reach these outcomes, "clinical remission' is the golden key, meaning, that the patient should be in a state of 'absence of signs and symptoms of disease activity'. The BeST trial provides all information obtained using different therapeutic strategies in active patients with RA with and without autoantibodies (rheumatoid factor-RF and or anticyclic citrullinated protein autoantibodies-ACPAs). Since the BeST also has X-ray baseline data, patients could also be stratified according to the baseline existence of joint damage.

The data discussed in the present study by Akdemir et $a l^{5}{ }^{5}$ which is a subanalysis of the outcomes at 10 years of follow-up of the BeST trial, regard autoantibody (ACPA) negative patients and these data are therefore welcome because they can help to clarify whether the approach to ACPA-negative patients can be different or has to exactly follow the T2T strategy that we adopt in treating AAb (autoantibody), either RF or ACPA-positive patients.

One of the major conclusions of the study is that $76 \%(64 / 84)$ of patients on initial monotherapy (MTX-methotrexate mainly) failed to reach the treatment target of low disease activity (LDA) after 3 months. However, at 6 months, 39/84 (46\%) had reached LDA, and after 1 year and after 10 years the percentage of patients in DAS 44 remission was very similar between the upfront monotherapy and the Combo therapy. X-ray progression was minimal with all strategies. Yet an important percentage did not reach remission. 
A major drawback is that the ACPA-negative patients had confounding characteristics: almost $30 \%$ were RF positive and more than $60 \%$ were erosive. The first question therefore is: does the scientific community agree and accept that RF-positive ACPA-negative are similar to ACPA-negative patients in terms of the initial approach and prognosis? Are there clear-cut data showing that the ACPA-negative subset, with and without RF, behaves similarly? The subanalysis made in this study seems to disregard the role of RF. The RF-positive patients are reported to behave as ACPA negative. Yet we are left with the suggestion that the only important test is ACPA.

The most comprehensive review on the prognostic role of autoantibodies states that the combination of ACPA and RF is worse than ACPA or RF alone in decreasing order. ${ }^{6}$ In addition, it is well acknowledged that the level of disease activity and mostly erosions at baseline are relevant in predicting future erosions, independently of autoantibodies. ${ }^{7}$

The second major conclusion of the study is that the upfront Combo therapy (either with csDMARDs or bDMARDs-biological DMARDs) gave fastest clinical control in terms of disease activity and function (health assessment questionnaire), whereas the final outcome in terms of joint damage assessed through radiography did not disclose any difference among the various therapeutic strategies since it was mild and clinically almost irrelevant. No differences emerged among the treated groups in terms of side effects and either mild or severe adverse events. The authors therefore suggest that, when the disease is very active, there should not be any differentiation between RF-positive and RF-negative patients. The take home message would be that rheumatologists should target disease activity irrespectively of the other prognostic factors (radiographic damage and RF and/or ACPA positivity) considered in the recommendation number 8 . Obviously, this message would contend that there are patients with RA needing only monotherapy using csDMARDs as well as those needing rapid intervention with Combo or bDMARDs. The main conclusion would be that patients with high disease activity along with already existing joint damage and or RF positivity will not face a poor prognosis if treated with Combo therapy, provided they are ACPA negative. Again, the confounding of RF positivity along with the erosive features already present at baseline do not allow the distinguishing of possible different outcomes among the two major seropositive subsets (ACPA positive vs RF positive) or not having radiographic damage at baseline.

At present, no data exist in the literature on the irrelevance of RF positivity in the long-term outcome of RA. In fact, in the BARFOT cohort, the predictive values for radiological damage and progression in patients with positive tests for both anti-CCP and RF were similar to those in patients who were positive for only one of the two tests, ${ }^{8}$ and in the cohort the receiver-operating characteristic curves for the progression of the modified total Sharp score (mTTS) were similar for RF and ACPA, with the ACPA positivity being more informative. ${ }^{8}$ Therefore, the data from the real world would suggest not disregarding RF positivity.

The other side of the coin is represented by the Canadian data from the Catch database. Shu et a $\ell^{9}$ suggest that even testing for ACPA positivity is not strictly necessary since the outcome at 3 months in terms of disease activity or health assessment questionnaire (HAQ), in persistent synovitis of more than 6 weeks duration, did not change if patients were divided among those seropositive for ACPA and/or RF, seronegative for both or unknown (because not tested). These very shortterm data would suggest that the initial therapy with csDMARDs could be started even without knowledge of the autoimmune serology.

These are provocative data that emphasise the discrepancy existing between the recommendations made by the experts on the basis of the evidence, and the application of the rules that should be adopted in the real world.

Very likely, some of the predictors still considered very important could vanish if another predictor, namely, disease duration of less than 12 weeks, is adopted as a discriminant factor for the major final outcomes (remission and no further damage), ${ }^{10}$ but this has yet to be proven. The subanalysis data of the BeST trial on ACPA-negative patients with RA certainly allow us to move forward: monotherapy with MTX in very active RA very unlikely will provide major benefits, while Combo therapy, from the beginning, will likely provide benefits without major safety concerns in ACPA-negative patients with RA even when RF is positive and the disease is erosive.

To correctly approach the RA syndrome, we certainly need more data from the real world-before changing the T2 T strategy-(1) that foresees 3 months with MTX, and then three more months with the same csDMARD if there is evidence of an improvement before changing therapy, or adding on, and (2) to stratify the patients according to disease activity plus ACPA and/or RF positivity, and by using structural damage as predictors to define the most appropriate therapeutic algorithm even in ACPA negative RA. Therefore, the answer to the question-'Should we maintain the T2T strategy even in ACPA-negative patients?'-is YES.

\section{Competing interests None declared.}

Provenance and peer review Commissioned; externally peer reviewed.

Data sharing statement No additional data are available.

Open Access This is an Open Access article distributed in accordance with the Creative Commons Attribution Non Commercial (CC BY-NC 4.0) license, which permits others to distribute, remix, adapt, build upon this work noncommercially, and license their derivative works on different terms, provided the original work is properly cited and the use is non-commercial. See: http:// creativecommons.org/licenses/by-nc/4.0/ 


\section{REFERENCES}

1. Combe $B$, Landewe $R$, Lukas $C$, et al. EULAR recommendations for the management of early arthritis: report of a task force of the European Standing Committee for International Clinical Studies Including Therapeutics (ESCISIT). Ann Rheum Dis 2007;66:34-45.

2. Smolen JS, Breedveld FC, Burmester GR, et al. Treating rheumatoid arthritis to target: 2014 update of the recommendations of an international task force. Ann Rheum Dis 2016;75:3-15.

3. Smolen JS, Landewé R, Breedveld FC, et al. EULAR recommendations for the management of rheumatoid arthritis with synthetic and biological disease-modifying antirheumatic drugs: 2013 update. Ann Rheum Dis 2014;73:492-509.

4. de Vries-Bouwstra JK, Goekoop-Ruiterman YP, Verpoort KN, et al. Progression of joint damage in early rheumatoid arthritis: association with HLA-DRB1, rheumatoid factor, and anti- citrullinated protein antibodies in relation to different treatment strategies. Arthritis Rheum 2008;58:1293-8.

5. Akdemir G, Markusse I, Dirven L, et al. Effectiveness of four dynamic treatment strategies in patients with anti-citrullinated antibody-negative rheumatoid arthritis - a randomised trial. RMD
Open 2016; Published Online First Mar 2016. doi:10.1136/rmdopen2015-000143

6. Rantapää-Dahlqvist S. Diagnostic and prognostic significance of autoantibodies in early rheumatoid arthritis. Scand J Rheumatol 2005;34:83-96.

7. van Nies JA, van Steenbergen HW, Krabben A, et al. Evaluating processes underlying the predictive value of baseline erosions for future radiological damage in early rheumatoid arthritis. Ann Rheum Dis 2015;74:883-9.

8. Forslind $\mathrm{K}$, Ahlmén M, Eberhardt $\mathrm{K}$, et al. BARFOT study group. Prediction of radiological outcome in early rheumatoid arthritis in clinical practice: role of antibodies to citrullinated peptides (anti-CCP). Ann Rheum Dis 2004;63:1090-5.

9. Shu J, Bykerk VP, Boire G, et al. CATCH Investigators. Missing anticitrullinated protein antibody does not affect short-term outcomes in early inflammatory arthritis: from the Canadian Early Arthritis Cohort. J Rheumatol 2015;42:2023-8.

10. Gremese E, Salaffi F, Bosello SL, et al. Very early rheumatoid arthritis as a predictor of remission: a multicentre real life prospective study. Ann Rheum Dis 2013;72:858-62. 